\title{
NOTAS SOBRE POEMAS Y POETAS HISPANOHEBREOS
}

\author{
¿UN NUEVO POEMA BÁQUICO DE SEMU EL HA-NAGID*
}

El tema del vino, con viejas raíces en el mundo clásico, se encuentra ya plenamente introducido en la poesía secular de los judíos españoles desde el siglo $x$, cuando Dunašben Labrat no duda en tomar los temas y motivos profanos de sus coetáneos árabes, expresándolos tal vez por primera vez en la lengua de la Biblia. Yyṣhaq ibn Jalfún, el poeta errante, lo incluye así mismo en su repertorio. Pero será Semu'el ibn Nagrella ha-Nagid, el gran político y poeta de Granada en la primera mitad del siglo xı, el que sabrá dar a estos temas, aparentemente convencionales e intranscendentes, una belleza, profundidad y gracia capaz de consagrar definitivamente el género dentro de la poesía secular hispanohebrea.

Más de treinta poemas de Semu'el ha-Nagid tocan directa o indirectamente el tema del vino: sus cualidades, sus efectos, la invitación a la bebida, descripción de los festines o symposia, etc. ${ }^{1}$ Al leer estos poemas sentimos llegar hasta nosotros un toque de ingenio, de despreocupación festiva, de alegría de vivir, trasplantados de otros ambientes y culturas muy distintos a ese clima espiritual austero del judaismo tradicional. Nos sentimos testigos de las veladas y tertulias con las que llena sus ratos de ocio la alta sociedad granadina del siglo XI. Y, no pocas veces, presenciamos a través de unas breves líneas la tensión que se produce entre la exigencia religiosa y el impulso vital en el interior de: una persona que por encima de todo se siente profundamente fiel al Dios de su pueblo.

"He reunido en estas páginas una serie de nuevos datos sobre poemas y poetas hispanohebreos, resultado de una parte de mis trabajos en los fondos manuscritos de la Genizah conservados en Cambridge University Library, a cuya dirección debo agradecer las facilidades y ayuda recibidas.

${ }^{1}$ Cf. mi trabajo sobre la poesía báquica de Semu'el ha-Nagid en Estudios sobre literatura y arte dedicados al profesor Emilio Orozco Días, Universidad de Granada, 1970, t. 3, pp. 221 ss. Está en prensa otro trabajo mío sobre "Bacchic and bellic poetry of Semu'el ibn Nagrella ha-Nagid" en The American Sephardi. 
La obra poética de Semu'el ha-Nagid de tema secular resultaba prácticamente desconocida en Occidente hasta que en 1934 publicó D. S. Sassoon su Diwan, sacando a la luz centenares de composiciones poéticas de uno de los más indiscutibles poetas que brillaron entre los judíos hispanos. Es significativo sin embargo que esa edición se hiciera a partir de un solo manuscrito (ms. Sassoon 589).

Entre la edición de Sassoon, y la más reciente, de Dov Yarden (1966), el conocimiento de manuscrito con poemas de ha-Nagid -especialmente, fragmentos de la Genizah de El Cairo conservados en Cambridge, Oxford, New York, etc. - ha crecido de manera substancial: la lista de manuscritos y fragmentos utilizados en la edición de Yarden ocupa tres páginas casi completas (pp. 345-347). Como es lógico, la posibilidad de que se encuentren nuevos fragmentos está todavía abierta, y no puede afirmarse que conozcamos ya la totalidad de la obra poética de Semu'el ibn Nagrella.

Trabajando recientemente en los fondos de la Genizah conservados en la Cambridge University Library, he tenido ocasión de encontrar un fragmento que parece ser parte de un diwan de Semu'el ha-Nagid, y en el que, junto a otros poemas suyos ya editados se halla un poema breve de tema báquico, al parecer inédito, y que muy razonablemente puede pensarse escrito por el mismo poeta y visir de Granada. Se trata del fragmento T.-S. N.S. 193.71. Aunque Yarden conoció y utilizó alguno de los fragmentos del álbum T.-S. N.S. 193, el fragmento a que nos referimos no se encuentra recogido en la lista de manuscritos por él utilizados, ni el poema al que aludimos ha sido incluido en su edición.

El fragmento, de unos 12 × $10 \mathrm{cms}$, escrito por una sola cara, contiene:

a) Restos de las tres últimas líneas de un poema de tema báquico.

b) El pequeño poema que creemos merece especial atención: cuatro versos de tema báquico (entrelazado en el último con el tema amoroso, como es frecuente en el género), precedido del epígrafe

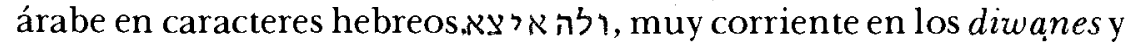
recopilaciones de versos de un mismo autor. Este encabezamiento, que atribuye el poema "al mismo" autor, y que se repite en los dos poemas siguientes, nos hace pensar con bastante probabilidad que se trata de un poema de Semu'el ibn Nagrella.

c) El poema de Semu'el ha-Nagid que en la edición de Yarden ha recibido el número 144, (ידרדף לבך המר), con el mismo encabezamiento árabe, y también de carácter báquico.

d) Los dos primeros versos del poema núm. 152 de la edición de Yarden ( רוךר באיר ) del mismo Semu'el ha-Nagid, igualmente de tema báquico, y con el mismo encabezamiento en árabe.

El estado en que se encuentran las últimas líneas del primer poema no nos permite reconstruirlo, ni aventurar una hipótesis 
sobre su posible autor, si bien algunas palabras nos inclinan a clasificarlo también como báquico.

Por lo que al segundo poema se refiere, además de las razones externas ya indicadas que podrían apoyar su atribución a Semu'el ibn Nagrella, a pesar de su temática un tanto convencional tiene unas características de lenguaje, estilo e imágenes perfectamente acordes con los de otros poemas del mismo autor; incluso pueden señalarse numerosos pararelos de los motivos más destacables que aparecen en el poema en otros del mismo Semu'el'2. Todo ello vendría, pues, a dar mayor fuerza a nuestro intento de atribución.

El fragmento tiene vocalizadas únicamente algunas palabras del poema, mezclando vocales supralineares y tiberienses. Su lectura no es siempre fácil y resulta especialmente dudosa en los finales de verso, y de modo particular al comienzo y fin del último, donde la reconstrucción de las palabras es muy poco segura. La última palabra se ha reconstruido de acuerdo con una sugerencia verbal del Dr. D. Yarden.

He aquí la reproducción del texto hebreo del poema, respetando la vocalización del manuscrito:

$$
\begin{aligned}
& \text { בת כמו ה̌אות והמוֹפת. }
\end{aligned}
$$

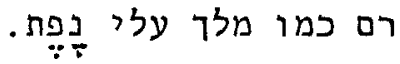

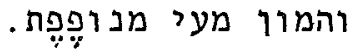

$$
\begin{aligned}
& \text { על יד צבי משקת מרחפת נישת. }
\end{aligned}
$$

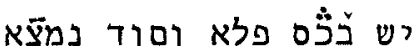

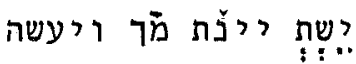

$$
\begin{aligned}
& \text { אם יגון לבי מעופפת } \\
& \text { לב יצתיני (אש)בכוסות }
\end{aligned}
$$

Hay en la copa un pordigio, y un secreto se da / en ella como signo y señal:

el que bebe su vino se debilita, mas se siente / tan elevado como un rey sobre la altura.

Si la pena de mi corazón revolotea, / ella hacedesaparecer la conmoción de mis entrañas.

El corazón me enciende con las copas / por la mano de la gacela que escancia aleteando.

La métrica del poema es regular; aunque no se ajusta exactamente a ninguno de los metros tradicionales, está próxima al ha-galu'a. Cada hemistiquio está compuesto de tres pies: på̃alulim / pačalulim / pal.

Pueden reconocerse algunos defectos posibles de transmisión en el segundo verso, la última del delet según el manuscrito, pertenece en

${ }^{2}$ Un paralelo a la comparación con el rey puede encontrarse en la p. 138 (v.53) de la edición de Yarden. El tema de que el vino aleja las penas del corazón es bien conocido dentro del género. Cf. mi trabajo citado en la nota anterior, pp. 227 ss. La paradoja debilidad/fortaleza y la comparación con el juego son también predilectos dẻ Semu'el, como puede comprobarse en dicho artículo. 
realidad al soger; al comienzo del soger del tercer verso se ha perdido una sílaba larga (que podría ser el pronombre, el artículo o la conjunción copulativa); en el cuarto verso, la primera palabra del soger según el manuscrito, pertenece realmente al delet; hemos eliminado además la palabra,א, que no es necesaria y rompe el esquema métrico. Estas pequeñas correcciones son suficientes en mi opinión para reconstruir el esquema métrico originario que a pesar de no ser ninguna de las variantes reconocidas en la variada obra poética de ha-Nagid, se da en otros poetas hispanohebreos y no ofrece dificultad especial.

Por lo demás, el contenido del poemilla es un tanto convencional: los efectos del vino, casi siempre expuestos en forma de paradoja o contraste, y muchas veces, como aquí, en el lenguaje dialéctico de la debilidad y la fortaleza; el tema del vino como factor que aleja las penas del corazón es igualmente tópico dentro del género; la comparación con el fuego, lo mismo que la aparición del copero que cautiva el corazón del poeta son también motivos bien conocidos en la poesía báquica tradicional, y especialmente dentro de la producción de Semu'el. El conjunto sin embargo no deja de tener esa belleza intrascendente que caracteriza a este tipo de composiciones breves y ligeras, casi un ejercicio conceptual, verbal y de imágenes, hermosamente armonioso.

\section{¿Nuevos poemas de Selomoh ibN Gabirol?}

Otro fragmento de la Genizah procedente también del fondo Taylor-Schechter de la Cambridge University Library podría tener un interés muy especial: se trata del ms. T.-S. N.S. 194. 46, en el que se encuentran siete poemas breves con diversos encabezamientos:

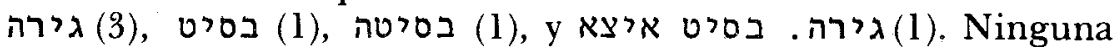
referencia concreta de autor permite identificarlos con certeza absoluta. La forma en que están recopilados, así como los encabezamientos, sugieren una posible unidad de autor; especialmente teniendo en cuenta que los temas y géneros son bastantes diversos, y que aun predominando los de contenido religioso, no se trata de poemas sacros escritos para la liturgia judía.

Uno solo de estos poemas ha sido anteriormente editado; su autor es bien conocido: el poeta malagueño Selomoh ibn Gabirol. Por las razones que indicamos, el resto de los poemas podrían ser también suyos. Sin embargo, el hecho de que resulte difícil encontrar en varios de ellos los esquemas métricos cuantitativos tradicionales podría hacer pensar que no proceden de la escuela hispanohebrea. El interrogante debe, en consecuencia, permanecer abierto.

El poema conocido y publicado, obra de Selomoh ibn Gabirol, ocupa el segundo lugar dentro del fragmento, y lleva el epígrafe de מה גירה תפחדי נפשי, Se trata del poemaido en las principales 
ediciones de Ibn Gabirol, como las de Bialik-Rawnitzki, BrodySchirmann, Yarden, etc., y clasificado generalmente entre los poemas seculares de tema ético. Sin embargo, las peculiaridades textuales que presenta la versión del fragmento merecen una atención especial.

A diferencia de los manuscritos del poema que hasta ahora se conocían, y que han sido recogidos en la edición de Schirmann, el poema tiene en este fragmento cinco en lugar de seis versos, omitiendo por completo el último verso incluido en todas las ediciones, y alterando notablemente el orden de los primeros: el quinto verso aparece aquí en segundo lugar, el segundo en tercer lugar, y el tercero en quinto lugar, dando fin al poema. Por lo demás, las variantes textuales propiamente dichas no son muy importantes.

Esta sería la traducción del poema en la forma que presenta el fragmento:

¿Por qué tiemblas, alma mía, por qué te asustas? Quédate y mora en el lugar en que resides.

Aunque el deseo de tu corazón sea como una ciudad fortificada, ¿no caerá en tu mano si pones un poco de cerco?

Si el mundo te parece pequeño como una mano, ¿dónde vas a buscar, infeliz arrastrada por la tormenta?

Cuando te apartes del hombre recibirás ayuda, y podrás ver el premio de tu obra.

Mejor que dirigirte hacia una u otra parte es que te sitúes ante tu Señor y no te alejes.

Debido a la unidad temática, el orden de los versos no altera sustancialmente el sentido global, y tanto ésta como la versión más extendida tienen su propia coherencia interna. La insatisfacción del poeta, su intranquilidad y su lucha con la tendencia excesiva a la búsqueda y la vida errante, son el tema presente en los versos. Sin embargo, mucha mayor importancia tiene en mi opinión la ausencia del último verso, que, aunque puede tener relación con el mismo tema, añade una modificación muy notable: la alusión al binomio del más acá y el más allá, los dos mundos de la escatología judía, que más bien parece fruto de una reelaboración posterior del poema que de un olvido más o menos intencionado. El verso que falta en el fragmento dice en las restantes manuscritos: "Tú no tienes heredad en la tierra. Despierta para buscar tu futuro, despierta".

El cambio de perspectiva respecto a los primeros versos es evidente: lo que allí eran reflexiones sobre el sentido de esta vida, se ha trocado en una dimensión distinta, la del mundo futuro. Todo parece indicar que el poema ha tenido dos versiones diferentes, y que la más breve, la contenida en este fragmento, es la más antigua. La versión más larga y difundida puede haber sido también obra del mismo Ibn Gabirol, desde luego, pero significa una modificación 
clara e intencionada de la primera versión, tal como se encuentra en nuestro fragmento.

Los seis poemas restantes tiene un contenido y forma muy diversos, y a pesar de que, como hemos indicado, pueden ser arte de un diwan de Ibn Gabirol, no podemos relacionarlos con este gran poeta de forma totalmente cierta. Ni siquiera el estudio de sus características internas nos permite, de momento, llegar más lejos en nuestra afirmación. No obstante, consideramos que presentan el suficiente interés como para merecer ser publicados.

El primero de los poemas tiene como tema la amistad, y recoge uno de los motivos tradicionales del género: el dolor por la partida de los seres queridos. Son cinco versos breves, con el esquema $p a^{c} a-$ lulim / po'alim / pocalim, aunque sin ajustarse a ninguno de los metros tradicionales, y con rima en-lu. La concisión, la precisión del lenguaje, el movimiento y el avance rápido de las ideas descubren la mano de un maestro bajo la aparente sencillez del texto:

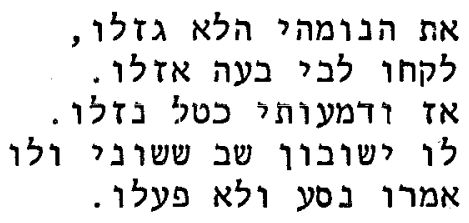

En verdad robaron mi sueño, se llevaron mi corazón cuando partieron.

En aquel momento destilaron mis lágrimas como rocío.

Ojalá volvieran: tornaría mi alegría, y aunque

dijeran: "parte", no lo lograrían.

El tercer poema lo forman cuatro versos desiguales (tal vez por problemas de transmisión), centrados en el tema de la ley, y en forma de recomendación o consejo del poeta a su propia alma. La estructura métrica se aparta también de los metros tradicionales, pudiéndose señalar, con ciertas dificultades, el siguiente esquema: milpa alim/, pacalulim /, nif ălim / p̌́c alim, sin cesura. Las rimas internas, en -mah en los dos primeros versos, y -bah en los dos últimos, permitiría igualmente la división en dos estrofas de versos muy breves y desigual número de sílabas. Las irregularidades podrían hacernos pensar también en falta de elaboración o en versos inacabados. Este es el texto del manuscrito.

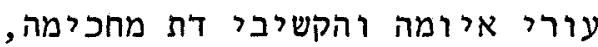

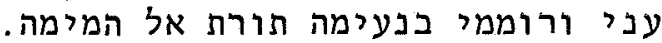

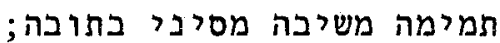

$$
\begin{aligned}
& \text { קיבלוה (בסובה) בעלי הישיבה בקובה מהול אהבה. }
\end{aligned}
$$

Despierta, temerosa, y escucha la Ley que hace sabios, toma la palabra y ensalza gustosa la Torah del Señor, perfecta. 
Sin defecto la trae del Sinaí escrita;

la reciben (dignamente) los jefes de la yešibahah con voces amorosas.

El cuarto poema, último del verso del fragmento, es muy breve: dos líneas con rima en -eha, fuera también de los esquemas métricos usuales, con referencia a las penas de la vida errante y a la relación entre el hombre y Dios. Epígrafe: basit. Este es su texto:

סופר נגדי וגם צערי עוד שימה בנאריך דמעה ותראיה. היטיב לנפש טובה מאר עושה דוה נדיבה גרת לסומכיה.

Tú que anotas mi huida y proteges mi marcha, recoge en tus odres el llanto para que puedas verlo.

¿Estará bien que el alma excelente y magnánima irrite al que la sostiene?

En el quinto poema, de cuatro versos con rima medial y final en $-d i$, es Dios mismo el que habla, prometiendo la restauración al pueblo elegido, tema especialmente querido para los poetas hispanohebreos.

Texto:

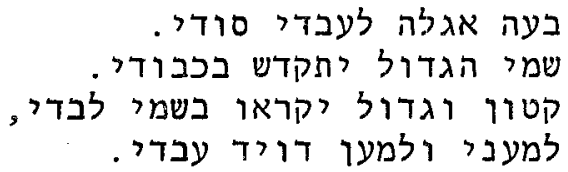

Construiré mi casa y fortificaré mi fundamento cuando revele a mi siervo mi secreto.

Estableceré firmemente sobre vosotros mi majestad, mi gran nombre será santificado por mi gloria.

He nombrado y creado todo para gloria mía, pequeño y grande serán llamados tan solo por mi nombre.

y mi techumbre estará sobre esta ciudad por mi bondad, a causa de mí y de David. mi siervo.

El sexto poema presenta el tono peculiar de las composiciones de liberación y esperanza, las gé ulot. Son dos estrofillas compuestas cada una de ellas de tres versos con número desigual de sílabas y rima en - $h_{i},-$-rib, más una palabra con rima en -si como enlace entre las dos estrofas. Epígrafe: basitah. Texto:

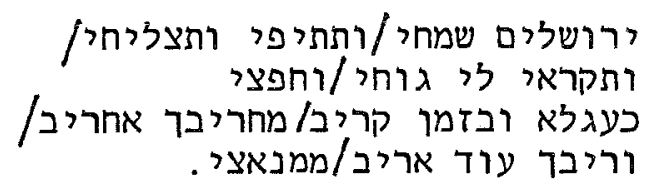


Jerusalén alégrate, hermoséate, siéntete realizada, grítame, salta y regocíjate como una ternera, pues en breve tiempo al que te ha destruido destruiré, y pleitearé tu causa contra el que te desprecia.

Finalmente, el último poema recogido en el fragmento, también de carácter religioso, presenta no pocas dificultades de lectura, debido al estado del papel. Lo forman ocho versos con rima medial y final en -ti, que no se ajustan a un esquema métrico cuantitativo regular. Es una súplica en busca de ayuda y consuelo. Epígrafe:גירה. בסיט איצא.Texto:

$$
\begin{aligned}
& \text { סלעי ומצודתי }
\end{aligned}
$$

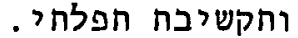

$$
\begin{aligned}
& \text { ל. שתילי בניכח מפלתי. }
\end{aligned}
$$

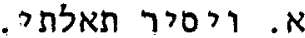

$$
\begin{aligned}
& \text { וחליני ציצור לביתי. }
\end{aligned}
$$

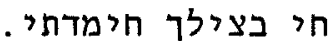

$$
\begin{aligned}
& \text { זבול קרשך איל חימיחי. } \\
& \text { סברי גם תוחלחי }
\end{aligned}
$$

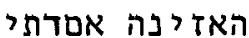

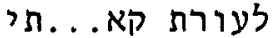

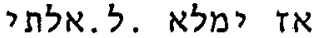

$$
\begin{aligned}
& \text { נחמיני גלי גם עדתי ליאלתי } \\
& \text { חונסן ישועי ניעם }
\end{aligned}
$$

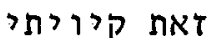

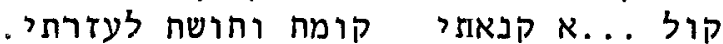

Esperanza y aspiración mía Roca y fortaleza mía, escucha mis palabras y presta oído a mi oración.

[...] plantones en mi heredad.

Entonces se cumplirá mi promesa y se alejará mi maldición.

Consuélame, y también a mi conmunidad, y hazme morar, oh Roca,en mi casa.

Apiadate, salvación mía, que viva bajo tu sombra mi deseo.

Esta es mi esperanza: tu santa morada yo anhelo.

De la voz...siento celo, levántate y apresúrate en mi ayuda.

\section{NUEVAS IDENTIFICACOONES DE POEMAS Y POETAS}

Las notas que siguen se refieren a varios poemas ya editados y recogidos incluso en el Thesaurus de Davidson, sobre los que nos ofrecen nuevos datos algunos fragmentos de la Genizah. Al trabajar sobre los fragmentos poéticos de la colección Taylor-Schechter de la Cambridge University Library, he encontrado varios fragmentos que considero de notable interés, ya que atribuyen a poetas concretos hispanohebreos algunos poemas hasta ahora considerados como de otros autores, o tenidos por obra de autor no identificado. Naturalmente, el que un manuscrito de la Genizah atribuya expresamente un poema a un autor determinado, no es garantía de que esa autoría sea cierta e incontrovertible: cabe perfectamente el que a lo largo de la transmisión textual del poema se haya podido introducir un dato falso, especialmente teniendo en cuenta la tendencia a buscar un personaje famoso como autor de toda composición. Sin embargo, aun admitiendo cierto margen de posible error, los nuevos datos que ofrecen estos fragmentos deben considerarse como signifi- 
cativos e importantes, e incluso como probablemente ciertos mientras razones internas no demuestren lo contrario.

a) A Yosef ibn Abitur ben Satanás, oriundo de Mérida y estrechamente relacionado con la comunidad judía de Córdoba en la segunda mitad del siglo $\mathrm{X}$, se atribuyen dos poemas generalmente considerados como escritos por otros autores distintos.

El primero de ellos, אזכרה מצו (Davidson 2287 ), es una conocida sèlihaha o composición penitencial para uno de los antiguos días de ayuno, el 10 del mes de Tebet. El poema, editado en numerosos libros judíos de oración, es atribuido a Ben Satanás en el fragmento T.-S. N.S. 110.1. El poema es alfabético, y tiene en la última estrofa el siman o acróstico YOSEF. Zunz ${ }^{3}$ consideraba esta última estrofa como una adición posterior. Sin embargo, la mención del autor que antecede al poema en el fragmento mencionado apoyaría la autenticidad de la misma. Parece igualmente desprovista de fundamen to la opinión de ciertos autores, recogida por Davidson, que atribuyen el poema a Yosef Tov. A la vista del dato que recogemos, esta composición puede considerarse escrita por el poeta hispanohebreo. He aquí la traducción:

Recordaré la aflicción que me ha sobrevenido:

con cuatro golpes me ha aplastado este mes;

me ha derribado, me ha aplanado, me ha aniquilado, me ha abatido; y ahora en verdad he sido rechazado.

Me empuja su día octavo por la izquierda y por la derecha, ¿acaso no me he fijado un ayuno de tres días?

El rey heleno me obligó a escribir la Ley en griego;

sobre mi espalda araron los labradores que dieron larga respuesta.

Me entristezco su día noveno por la ignominia y la vergüenza: me fue retirado el manto de hermosura y belleza.

Ese día fue expoliado totalmente el que dice hermosas palabras, Esdras el Escriba.

En su día décimo se le ordenó al hijo de Buzí el vidente: escribete el nombre hoy en el libro de la visión, como recuerdo para el pueblo humillado y despreciado, en este mismo día.

El número del orden de los meses el día quinto hago notar; con lamento y sollozo abro en él mi boca.

La serie de los castigos arde dentro de mi corazón, cuando se acerca el mensajero diciendo: ha sido castigada la ciudad.

He esparcido polvo sobre mi rostro, y por ellas me he excavado una tumba estrecha; he quedado hendido por las cuatro como si hubiera lanzado una flecha contra mi corazón.

Justo es el Señor cuyo mandato he desobedecido.

He invocado tu nombre que se compadece de mi maldad. 
Mira mi indigencia y escucha la voz de mi plegaria.

Has oído mi súplica, acelera mi liberación.

¿Vas a cerrar tus oídos a mi espíritu ante mi quejido?

En el mes de Tebet he sufrido mucho;

los órdenes de su nombre y su camino se han cambiado contra mí. He porfiado en mi delito, descúbreme los órdenes de su bondad, Tú que dices al mar: hasta aquí puedes llegar ${ }^{4}$.

Otro fragmento de la Genizah, T.-S. N.S. 325. 174 atribuye al mismo Yosef ibn Abitur el poema אשכימה שהר (Davidson א 8076), cuyo siman indica: YOSEF BE-RABI YIS HAQ HZQ, y que tanto Landshuth $^{5}$ como Dukes ${ }^{6}$, y el mismo Davidson consideran como escrito por Yosef Qimhi. Tendríamos probablemente un nuevo poema de Ibn Abitur en esta composición, publicada en el Mahazor de Trípoli y conocida largo tiempo ha.

b) No es nueva la atribución a Mošehibn 'Ezra de un poema de Purim bastante conocido: המן נלהץ (Davidson ה 778). El poema se encuentra en el Malhazor Romanía, y tanto Dukes ${ }^{7}$, como Landshuth ${ }^{8}$, Luzzatto ${ }^{9}$, etc., lo consideran como obra de Mošeh ibn 'Ezra, el gran poeta granadino. El acróstico del poema lee únicamente MOŠEH HZQ, por lo que en principio cabría la atribución a cualquier paytan llamado Mošeh. Tanto Zunz ${ }^{10}$ como Davidson lo consideran como probable obra de Mošeh ben Sělomoh Gerondí de Escola, paytan catalán del siglo XII, sobrino de la mujer de Nahmánides. Otro fragmento de la Genizah conservado en la Biblioteca de la Universidad de Cambridge, T.-S., N.S. 299.8, lo atribuye expresamente a Abi ha-arun (=Moseh) ibn 'Ezra. Esta referencia expresa al poeta de Granada nos inclina a considerar el poema como obra suya, a pesar de que no suele incluirse entre los poemas editados de Mošeh ibn 'Ezra: ni Bialik-Rawnitzki, ni Brody ni Bernstein lo han incluido en sus respectivas ediciones.

En diferentes fragmentos de la misma colección he podido localizar otros poemas de Mošeh ibn 'Ezra ya editados bajo su nombre, y que indico aquí con objeto de que pasen a engrosar las listas de

\footnotetext{
${ }^{4}$ Según la tradición rabínica, tres calamidades ocurrieron al pueblo judío durante el mes de Tebet: el día 8 concluyó la traducción de la Torah al griego (le Septuaginta), hecho considerado por los rabinos como una gran tragedia para el judaismo (por los cambios y adaptaciones de la traducción y su posterior utilización por los cristianos); el día 9 se conmemora la muerte de Esdras y Nehemías; el día 10, en el que se celebra un ayuno especialmente solemne, coincide con el cerco de Jerusalem por Nabucodonosor (Je 52, 4). Son los tres acontecimientos mencionados en el poema.

${ }^{5}$ Amude ha-'aboda, p. 91.

- Moses ben Esra aus Granada, p. 17:

${ }^{7}$ Loc. cit, p. 9.

${ }^{8}$ Loc. cit., p. 250.

${ }^{9}$ Luah nahalat $S D L$, p. 58.

10 Literaturgeschichte der Syn. Poesie, pp. 403, 482.
} 
manuscritos conocidos de las obras del granadino: T.-S. N.S. 299. 139, משאת שיר (Davidson K 3831), T.S. N.S. 325. 152a)

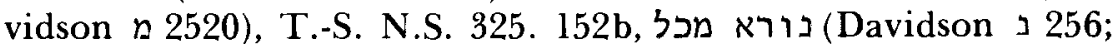

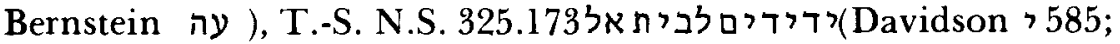

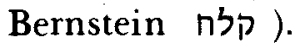

c) El poeta hispanohebreo Yosef ibn Șaddiq (1080-1149) es conocido tanto por su producción poética como por su obra filosófica. El fragmento T.S. N.S. 194.33 (verso) le atribuye expresamente un denso poema ya conocido, pero cuyo autor no había sido identificado hasta ahora:Davidson , 3463). El poema está formado por cuatro estrofas con pizmon (el fragmento mencionado no llega al final de la tercera estrofa), con el acróstico YOSEF. Davidson no intenta precisar más la identidad de su autor, y Zunz ${ }^{11}$ incluye el poema entre los escritos por "Yoseph", la mayor parte de origen hispano y de época indeterminada. El dato aportado por nuestro fragmento podría develar definitivamente la incógnita del nombre de su autor. El carácter filosófico del poema, en el que la filosofía neoplatónica juega un importante papel,vendría a aumentarlas probabilidades de que la atribución hecha por el fragmento sea exacta.

He aquí la traducción de la parte de poema conservada en el fragmento:

Se seduce a la doncella hermosa oculta a la vista: los que tienen mente inteligente saben dónde, cómo y por qué.

(Pizmon)

Desciende a una casa de barro cuando se juntan el cuerpo y la forma, y está oculta allí sin ansiedad, aunque prisionera;

no puede ser capturada con la mano, es posible transmitirla sin dinero; para trabajar la tierra del cuerpo y para darle hermosura y espanto, fuerza y cordura de mente para diferenciarlo de las bestias.

(Pizmon)

La hermosura de tu acción prodigiosa es demasiado sublime, oh Roca, para entenderla.

El espendor de tu creación es como el hombre que funde el oro blanco.

El es lo primeo de tu cosecha, y $[\ldots]$ de la paja.

El poder de tu mano reúne mi embrión con el alma,

establece la forma del aspecto de mi emagen a partir de la tierra.

(Pizmon)

Pide liberarse de su esclavitud en la vida,

el día en que se toma respiro, y no se hace pesado el trabajo, pues el fundamento del alma viva es la corrupción, y muere el día de la separación.

"Loc. cit., p. 573. 
[...] (falta el final de esta estrofa, y la siguiente).

El contenido del poema resulta así coherente con la cultura filosófica de Ibn Șaddiq.

d) Finalmente, el fragmento T.-S., A.S. 111.169 atribuye expresamente a Selomoh ben Sahal una maqama que conocemos gracias בן יהוד . באום אשר.Lo importante en este caso es la forma misma del nombre del poeta conservada en el citado fragmento. El nombre de este poeta hispanojudío se conoce tradicionalmente como Selomoh ibn Șaqbel. de acuerdo con la referencia que del mismo se hace en el pasaje correspondiente del Taḥkěmoni de Yehudah Al-Harizí, y que sería interpretado de diversas maneras por los estudiosos ${ }^{13}$. Ha llamado siempre la atención el hecho de que Al-Harizí presente a este poeta como pariente de Yosef ibn Sahal, al mismo tiempo que - al menos en los manuscritos y ediciones del pasaje - le menciona como Ibn Saqbel. El mismo Schirmann, que recogería no menos de seis manuscritos fragmentarios en los que se encuentra esta maqama del poeta hispano, discute el problema de la posible identidad del poeta conocido como Ibn Saqbel y el Abu-Ayyūb ben Sahal al que se hace referencia en la introducción del poema en uno de los fragmentos por él citados.

El nuevo fragmento al que hacemos alusión, de la serie más recientemente clasificada en la Cambridge University Library, contiene el comienzo de la maqama (catorce líneas de unos $65 \mathrm{~mm}$.), con algunas variantes respecto al texto editado por Schirmann - aunque no lo suficientemente importantes como para merecer ser publicado en toda su extensión- y la atribuye como decíamos a Selomoh ibn Sahal. Estamos convencidos de que la forma del nombre del poeta que se recoge en el manuscrito es la correcta. Si ya Schirmann, al editar la maqama, insinuaba que Ibn Saqbel e Ibn Sahal podían ser una misma persona, a la vista de este nuevo dato me atrevería incluso a sugerir que Ibn Saqbel podría no ser otra cosa que la deformación paleográfía del verdadero nombre del poeta, que no sería otro que el que encontramos en nuestro fragmento, Selomoh ibn Sahal, de la familia ilustre y bien conocida de los Ibn Sahal andalusíes, de la primera mitad del siglo XII.

ÁNGEL SÁENZ-BADILLOS

Universidad de Granada.

\footnotetext{
${ }^{12}$ En Studies of the Research Institute for Hebrew Poetry, t. 12, 1936, pp. 152 ss.

${ }^{13}$ Cf. Steinschneider, JQR 11, 601, núm. 638.
} 